\title{
Genetic evaluation for semen characteristics in a crossbreeding project involving Saudi and Spanish V-line rabbits
}

\author{
M. H. Khalil ${ }^{1}$, K. A. Al-Sobayil ${ }^{1}$, A. M. Al-Saef ${ }^{1}$, M. L. García ${ }^{2 \dagger}$ and M. Baselga ${ }^{3}$ \\ ${ }^{1}$ Department of Animal Production and Breeding, College of Agriculture and Veterinary Medicine, Al-Qassim University, Buriedah, PO Box 1482, Al-Qassim, Saudi \\ Arabia; ${ }^{2}$ Departamento de Tecnología Agroalimentaria, Universidad Miguel Hernández, Centra Beniel Km 3.2 Orihuela 03312, Alicante, Spain; ${ }^{3}$ Departamento de \\ Ciencia Animal, Universidad Politécnica de Valencia, Camino de Vera 14, Apartado 22012, 46071, Spain
}

(Received 9 December 2006; Accepted 15 May 2007)

Two parallel schemes of crosses were practised involving the Spanish maternal line called V-line (V) and Saudi Gabali (S) rabbits. The first scheme began by crossing Saudi Gabali bucks with $V$-line does to get the $F_{1}$ cross $\left(\frac{1}{2} S \frac{1}{2} V\right)$, then does of this $F_{1}$ were backcrossed with bucks of $V$-line to get $\frac{3}{4} V \frac{1}{4} S$, then the progenies of the backcross were inter se mated to get $\left(\frac{3}{4} V_{\frac{1}{4}} S\right)^{2}$, followed by two more generations of inter se mating of $\left(\frac{3}{4} V \frac{1}{4} S\right)^{2}$ to get a new synthetic maternal line named Saudi 2 . The second scheme began by crossing $V$-line bucks with Saudi does to get the $F_{1}$ cross $\left(\frac{1}{2} V \frac{1}{2} S\right)$, then does of this $F_{1}$ cross were backcrossed with Saudi bucks to get $\frac{1}{2} S \frac{1}{2} V$, then progeny of this backcross were inter se mated to get $\left(\frac{3}{4} S \frac{1}{4} V\right)^{2}$, followed by two generations of inter se mating of $\left(\frac{3}{4} S_{4}^{2} V\right)^{2}$ to form a new synthetic paternal line named Saudi 3. A generalised least-square procedure was used to estimate differences between lines in direct and maternal additive effects, direct and maternal heterosis, and direct recombination losses. A total number of 2497 ejaculates of 642 bucks were evaluated for ejaculate volume (VE), $p H$ of semen, sperm concentration (SC), percentage of motile spermatozoa (MS), percentage of spermatozoa with abnormal form (AS), percentage of dead spermatozoa (DS) and libido score (LS). The estimates of direct additive effect for DS (14.2\%), SC (12.4\%) and AS (12.0\%) were moderate and favourable to Saudi rabbits. Maternal additive effects for VE (11.7\%) were in favour of genes of V-line carried by the dams of bucks, while these estimates were in favour of Saudi genes for DS (18.6\%), AS (13.2\%), MS (10.8\%) and SC (10.0\%). Positive estimates of direct heterosis recorded for SC (13.5\%), VE (10.6\%) and MS $(10.5 \%)$ and the negative estimates recorded for AS $(-21.5 \%)$ and DS $(-20.3 \%)$ were moderate and well disposed to semen parameters of crossbred bucks. Positive estimates of maternal heterosis for VE (24.0\%), MS (21.8\%), SC (10.3\%) and LS $(10.2 \%)$ of bucks, and the negative estimates for percentage of DS (-14.7\%) and AS (-9.6\%) were also significantly favourable. Estimates of direct recombination losses for the majority of semen traits were always not significant.

Keywords: additive effects, heterosis, rabbits, recombination losses, semen characters

\section{Introduction}

Semen characteristics are very important if we consider that one single male affects the fertility and prolificacy of many females, especially when artificial insemination (Al) is performed as a routine in rabbit farms (Alvariño, 2000). On the other hand, semen characteristics are important not only due to their relationship with male fertility and prolificacy (which are, in general, good) but also because they determine the number of doses that can be obtained from one ejaculate, and therefore, the efficacy of using bucks for Al. The objective of the Al centres is to obtain a greater number of doses at lower cost, and at the same time it should allow

\footnotetext{
† E-mail: mariluz.garcia@umh.es
}

semen production to be increased while maintaining a high level of male fertility and prolificacy. For rabbits to be raised in large-scale commercial production in hot climate areas, libido of bucks could affect negatively both conception and kindling rates. Therefore, bucks must be tested for libido behaviour in order to be used efficiently in any breeding programme.

Results on semen quantity and quality of crossbred males from sire lines could lead to a change in rabbit meat production schemes by using crossbred males in the terminal cross instead of purebred males (Egea De Prado and Roy Perez, 1992; Brun et al., 2002; Al-Sobayil and Khalil, 2002). Alvariño et al. (1996) reported that differences in semen parameters among paternal breeds could affect conception rates. Recently, García-Tomás et al. (2006a and b) indicated 
that the superiority of crossbred bucks has not been proved for Spanish sire lines and semen traits.

Vicente et al. (2000) in Spain observed considerable differences in seminal characteristics among males of rabbit lines. Brun et al. (2002) in France have reported significant heterotic effects on sperm concentration (SC), mass motility and percentage of motile sperm per ejaculate. Also, GarcíaTomás et al. (2006a) in Spain found a significant but negligible percentage of heterosis for sperm normalcy, a high percentage of heterosis for the two traits related to the presence of proximal and distal cytoplasmatic droplets in the spermatozoa and a non-significant heterosis effect for $\mathrm{pH}$. To date, publications concerning genetic analysis of semen parameters for crossbred rabbits raised in hot climate countries are very scarce. The objective of the present study was mainly to estimate direct and maternal heterosis, direct and maternal genetic additive effects, and recombination losses for semen characteristics of bucks in a crossbreeding project carried out in a hot climate country involving Spanish V-line (V) and Saudi Gabali (S) rabbits, with the intention to synthesise new maternal and paternal lines suitable for hot climates.

\section{Material and methods}

\section{Animals and breeding plan}

The rabbits used in this study represent one Saudi breed (Saudi Gabali, S) and one exotic breed (Spanish V-line, V). Saudi Gabali is a desert breed raised under the Saudi desert conditions especially in the Najd area and rabbits of this breed are characterised by a large litter size of six to eight young, a heavy mature body weight of 3.2 to $3.8 \mathrm{~kg}$ and the ability to survive and adapt to produce and reproduce in a hot environment. The V-line is a maternal rabbit line selected for number of young weaned per litter (Estany et al., 1989) for 21 generations. The size of the line is around 120 does and 25 bucks.

Eighty pedigree does and 16 pedigree bucks of V-line rabbits were imported from Universidad Politécnica de Valencia, Valencia, Spain, in September 2000. A 4-year crossbreeding project involving these two breeds was started in September 2000 in the experimental rabbitry, College of Agriculture and Veterinary Medicine, El-Qassim region to develop a maternal line and a paternal line of rabbits in Saudi Arabia.

The breeding plan in the project permitted connected production of 11 genetic groups as shown in Table 1. Two parallel schemes of crosses were undertaken. The first scheme began by crossing Saudi Gabali bucks with V-line does to get the $F_{1}$ cross $\left(\frac{1}{2} S \frac{1}{2} V\right)$, then does of this $F_{1}$ were backcrossed with bucks of V-line to get $\frac{3}{4} V \frac{1}{4} S$, then progeny of the backcross were inter se mated to get $\left(\frac{3}{4} V \frac{1}{4} \mathrm{~S}\right)^{2}$ and, finally, followed by two generations of inter se mating of the previous progeny $\left(\frac{3}{4} \mathrm{~V} \frac{1}{4} S\right)^{2}$ to get a new synthetic maternal line named Saudi 2 . The second scheme began by crossing V-line bucks with Saudi does to get the $F_{1}$ cross $\left(\frac{1}{2} \vee \frac{1}{2} S\right)$, then does of this $F_{1}$ were backcrossed with Saudi bucks to get $\frac{3}{4} S \frac{1}{4} \mathrm{~V}$, then progeny of this backcross were inter se mated to get $\left(\frac{3}{4} \mathrm{~S} \frac{1}{4} \mathrm{~V}\right)^{2}$ and, finally, followed by two inter se mating generations of $\left(\frac{3}{4} \mathrm{~S} \frac{1}{4} \mathrm{~V}\right)^{2}$ of the previous progeny to form a new synthetic paternal line named Saudi 3. The bucks were randomly assigned to mate the does naturally with the restriction to avoid matings of animals with common grandparents.

\section{Housing and feeding}

Rabbits were raised in a semi-closed rabbitry. Breeding does and bucks were housed separately in individual wire cages. All cages are equipped with feeding hoppers and drinking nipples. In the rabbitry, the environmental conditions were monitored; temperature ranged from $20^{\circ} \mathrm{C}$ to about $32^{\circ} \mathrm{C}$, the relative humidity ranged from $20 \%$ to $50 \%$ and the photoperiod was $16 \mathrm{~L}: 8 \mathrm{D}$. Young rabbits were weaned at 4 weeks of age. Rabbits were fed a commercial pelleted diet during the whole period. On a dry-matter basis, the diet contained $18.5 \%$ crude protein, $8.0 \%$ crude fibre, 3.0\% ether extract and $6.5 \%$ ash. Feed and water were available ad libitum.

\section{Semen collection and libido score}

Data collected for semen characteristics were available for bucks of all generations. The distribution of bucks used and their ejaculates produced in each genetic group are presented in Table 2. A total number of 2497 ejaculates collected from 642 bucks were evaluated for semen characteristics. Bucks were housed in individual cages and they were accustomed to ejaculate in an artificial vagina. The semen samples were collected from the bucks at an early age of 5 to 6 months. Three to five ejaculates per buck were collected in the morning with a collection interval of 2 weeks. Once the ejaculate had been collected, the volume (ml) was measured using a graduated tube. The ejaculates with abnormal colours (in case of the presence of blood or urine, etc.) or with gel were not evaluated. The samples were placed in an incubator $\left(37^{\circ} \mathrm{C}\right)$ for a period of 10 to 15 min to prevent cold shock. $\mathrm{pH}$ was measured by a $\mathrm{pH}$ meter and each ejaculate was evaluated manually and examined by microscopy. For measuring motility of spermatozoa, semen was diluted with $2.9 \%$ sodium citrate dihydrate solution $\left(37^{\circ} \mathrm{C}\right)$ and was recorded on a subjective scale of $0 \%$ to $100 \%$ after viewing several microscopic fields. Percentages of live, dead and abnormal sperm were recorded as described by Chemineau et al. (1991). Duplicate smears from each ejaculate were stained with eosin-igrosin stain. A total of 200 spermatozoa were examined randomly ( 100 in each of the two smears). Sperm cell concentration $\left(\times 10^{6} / \mathrm{ml}\right)$ was quantified by direct cell count using the improved Neubauer haemocytometer (Boussit, 1989).

Each ejaculate was examined for volume of ejaculate (VE), pH of semen, SC, percentage of motile spermatozoa (MS), percentage of spermatozoa with abnormal form (AS) 
Genetic evaluation for rabbit semen characteristics

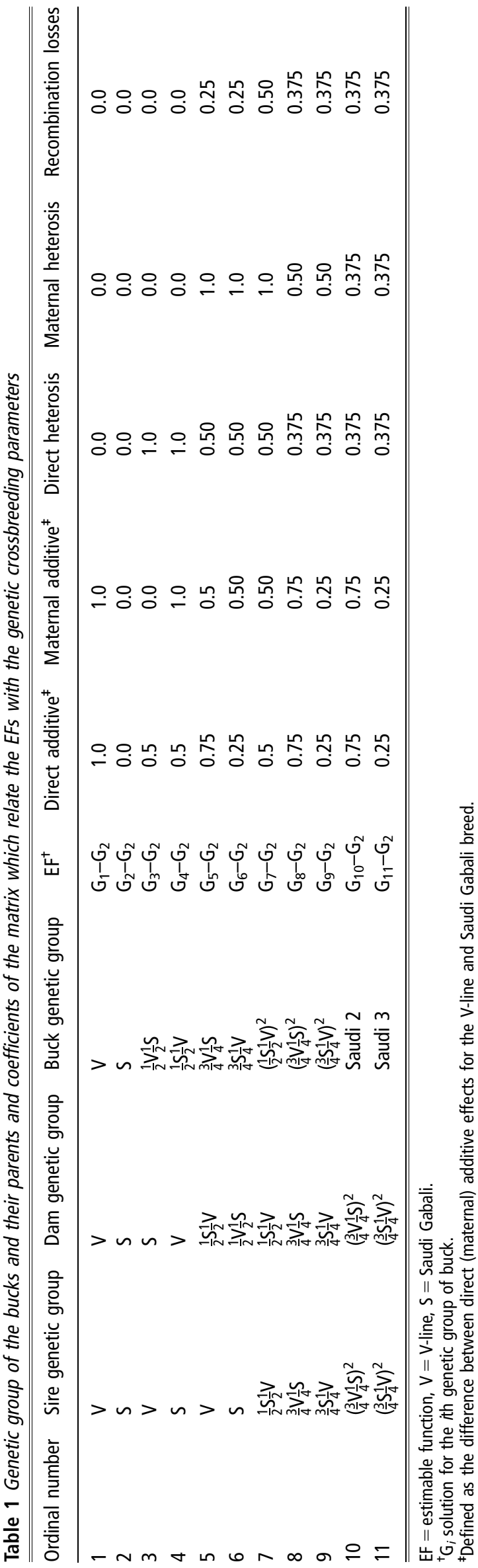

Table 2 Distribution of bucks used and semen ejaculates obtained in different genetic groups

Buck genetic group No. of bucks used No. of ejaculates obtained

\begin{tabular}{lrr}
\hline $\mathrm{V}$ & 68 & 238 \\
$\mathrm{~S}$ & 42 & 198 \\
$\frac{1}{2} \mathrm{~V} \frac{1}{2} \mathrm{~S}$ & 34 & 130 \\
$\frac{1}{2} \mathrm{~S} \frac{1}{2} \mathrm{~V}$ & 21 & 72 \\
$\frac{3}{4} \mathrm{~V} \frac{1}{4} \mathrm{~S}$ & 42 & 160 \\
$\frac{3}{4} \mathrm{~S} \frac{1}{4} \mathrm{~V}$ & 34 & 130 \\
$\left(\frac{1}{2} \mathrm{~S} \frac{1}{2} \mathrm{~V}\right)^{2}$ & 48 & 190 \\
$\left(\frac{3}{4} \mathrm{~V} \frac{1}{4} \mathrm{~S}\right)^{2}$ & 38 & 150 \\
$\left(\frac{3}{4} \mathrm{~S} \frac{\mathrm{V}}{4}\right)^{2}$ & 95 & 372 \\
Saudi 2 & 118 & 454 \\
Saudi 3 & 102 & 403 \\
Total & 642 & 2497 \\
\hline
\end{tabular}

V $=$ V-line, $\mathrm{S}=$ Saudi Gabali.

and percentage of dead spermatozoa (DS). At the time of semen collection for each ejaculate per buck, libido score (LS) of bucks was measured subjectively by giving the buck a score from 0 to 5 . The score of 1 was given to the bucks that showed low libido, and the score of 5 to those that exhibited strong libido (i.e. a sexually very active buck).

\section{Model of analysis and estimation of crossbreeding genetic parameters}

The animal model used in analysing the semen parameters was

$$
\mathbf{y}=\mathbf{X b}+\mathbf{Z}_{\mathrm{a}} \mathbf{u}_{\mathrm{a}}+\mathbf{Z}_{\mathrm{p}} \mathbf{u}_{\mathrm{p}}+\mathbf{e},
$$

where $y$ was the vector of observed semen parameter for bucks; $\mathbf{b}$ was the vector of fixed effects of the genetic group of buck (11 levels), year-season of semen collection (1-year season every 3 months); $\mathbf{u}_{\mathrm{a}}$ was the vector of random additive effect of the bucks and sires and dams of bucks; $\mathbf{u}_{\mathrm{p}}$ was the vector of random effects of the permanent nonadditive effect of the bucks; $\mathbf{X}, \mathbf{Z}_{\mathrm{a}}$ and $\mathbf{Z}_{\mathrm{p}}$ were the incidence matrices relating records to the fixed effects, additive genetic effects and permanent environment, respectively; and e was the vector of random residual effects.

The variance components of the random effects were estimated by REML using analytical gradients methodology implemented in the VCE software (Neumaier and Groeneveld, 1998). These parameters were used to solve the corresponding mixed model equations. The solutions obtained for estimable functions of the genetic groups (represented as the $\hat{g}$ vector) and the matrix of their estimated (co) variances $\left(\mathbf{C}{ }^{i}\right)$ were used to get the estimates of the crossbreeding genetic parameters of the lines, applying the procedure of generalised least-squares (GLS) using the CBE package of Wolf (1996). These estimable parameters represent the differences between direct genetic effects of the lines $\left(D^{\prime}=D_{\vee}^{\prime}-D_{\varsigma}^{\prime}\right)$, differences between maternal genetic effects of the lines $\left(M^{D}=M_{\mathrm{V}}^{D}-M_{\mathrm{S}}^{D}\right)$, individual 
heterosis $\left(H^{\prime}\right)$, maternal heterosis $\left(H^{M}\right)$ and recombination losses $\left(R^{\prime}\right)$ as stated by Dickerson (1992) and Baselga et al. (2003). The interpretation of $\hat{g}$ in terms of the genetic parameters of the crosses are given in Table 1, where the combination of parameters that explain the effects of different genetic groups of buck are $D_{v}^{\prime}-D_{s}^{\prime}, M_{v}^{D}-M_{s}^{D}, H^{\prime}$, $H^{M}$ and $R^{\prime}$ (the solution for the buck genetic group number 2 was equalled to 0 ). Thus, we have five parameters to estimate, included in the vector that we call $z$, thus

$$
z^{\prime}=\left[\begin{array}{lllll}
\left(D_{v}^{\prime}-D_{\mathrm{s}}^{\prime}\right) & \left(M_{\mathrm{v}}^{D}-M_{\mathrm{S}}^{D}\right) & H^{\prime} & H^{M} & R^{\prime}
\end{array}\right] .
$$

Since $z$ explains $\hat{g}$ through the following model:

$$
\hat{g}=\mathbf{X}^{\prime} z+\mathbf{e},
$$

with $\mathbf{X}$ being the matrix of incidence relating the solutions of buck genetic group effects with the parameters of crossbreeding (Table 1), the GLS solution for $z$, which we call $\hat{z}$, will be unique:

$$
\widehat{z}=\left(\mathbf{X}^{\prime}\left(\mathbf{C}^{i i}\right)^{-} \mathbf{X}\right)^{-1} \mathbf{X}^{\prime}\left(\mathbf{C}^{i i}\right)^{-} \hat{g},
$$

where $\left(\mathbf{X}^{\prime}\left(\mathbf{C}^{i i}\right)^{-} \mathbf{X}\right)^{-1}=$ the variance-covariance matrix of $\hat{z}$ needed to test the significance of the components of $z$.

\section{Results and discussion}

\section{Overall actual means for semen parameters}

Results in Table 3 describe the semen performance of bucks raised in the project. Most traits showed remarkable variability particularly in SC and percentages of MS. The ranges for semen parameters obtained (Table 3) were similar to those obtained by Kuzminsky et al. (1996), Minelli et al. (1999), Alvariño (2000), Arroita et al. (2000), Al-Sobayil and Khalil (2002) and Castellini et al. (2003). García-Tomás et al. (2006b) and Vicente et al. (2000) found marked differences in the overall means only for VE but not for the other semen characteristics in line R raised in Spain.

\section{Proportion of the phenotypic variance due to genetic} additive effects $\left(\mathrm{h}^{2}\right)$ and male permanent environmental and genetic non-additive effects $\left(p^{2}\right)$

We define $h^{2}$ and $p^{2}$ as the ratios of the additive variance and environmental permanent variance to the phenotypic variance, all of them estimated by REML analysis (Table 4).

Table 3 Summary statistics for semen characteristics and libido score

\begin{tabular}{lccccc}
\hline \hline Trait & No. of records & Mean & s.d. & Minimum & Maximum \\
\hline VE $(\mathrm{ml})$ & 2497 & 0.63 & 0.32 & 0.1 & 1.5 \\
pH & 2497 & 7.5 & 2.4 & 5.5 & 9.0 \\
SC $\left(10^{6} / \mathrm{ml}\right)$ & 2442 & 434 & 204 & 5.0 & 1080 \\
MS & 2456 & $65.7 \%$ & $28.3 \%$ & $5.0 \%$ & $95.0 \%$ \\
AS & 2482 & $14.6 \%$ & $6.2 \%$ & $0 \%$ & $45.0 \%$ \\
DS & 2466 & $8.1 \%$ & $3.8 \%$ & $0 \%$ & $40.0 \%$ \\
LS & 2424 & 4.4 & 1.4 & 1.0 & 5.0 \\
\hline
\end{tabular}

$\mathrm{VE}=$ volume of ejaculate, $\mathrm{pH}=\mathrm{pH}$ of semen, $\mathrm{SC}=$ concentration of sperm, $\mathrm{MS}=$ motility of sperm, $\mathrm{AS}=$ abnormal $\mathrm{sperm}, \mathrm{DS}=$ dead sperm, $\mathrm{LS}=$ libido score.
These parameters, it must be understood, are extended to the two lines and crosses involved in this experiment. Thus, the $h^{2}$, for example, has not the common meaning of heritability referring to a unique population in genetic equilibrium. The estimates of $h^{2}$ and $p^{2}$ were moderate, ranging from 0.12 to 0.18 and from 0.15 to 0.28 , respectively. They are lower than those estimates presented by Brun et al. (2002) in France and by García-Tomás et al. (2006b) in Spain.

\section{Direct and maternal additive effects}

The estimates of direct and maternal additive effects for semen parameters were mostly moderate and in favour of Saudi Gabali breed as shown in Table 5 .

Moderate and significant estimates of differences in direct additive effects for SC $(12.4 \%)$, percentage of DS $(14.2 \%)$ and percentage of AS $(12.0 \%)$ indicate that in the bucks, the Saudi genes had higher value than the V-line genes (Table 5). Also, García-Tomás et al. (2006a) stated that differences in direct genetic effects between two sire lines $(C$ and $R$ ) were significant and relevant for some

Table 4 Estimates of the proportion of the phenotypic variance due to genetic additive effects $\left(\mathrm{h}^{2}\right)$ and to permanent environment and genetic non-additive effects $\left(\mathrm{p}^{2}\right)$ with their standard errors ( \pm s.e.) for semen characteristics and libido score

\begin{tabular}{lcc}
\hline \hline Trait & $h^{2} \pm$ s.e. & $p^{2} \pm$ s.e. \\
\hline VE $(\mathrm{ml})$ & $0.13 \pm 0.020$ & $0.19 \pm 0.021$ \\
pH & $0.12 \pm 0.028$ & $0.23 \pm 0.028$ \\
SC $\left(10^{6} / \mathrm{ml}\right)$ & $0.12 \pm 0.026$ & $0.28 \pm 0.025$ \\
MS $(\%)$ & $0.18 \pm 0.025$ & $0.21 \pm 0.016$ \\
AS $(\%)$ & $0.16 \pm 0.023$ & $0.25 \pm 0.013$ \\
DS $(\%)$ & $0.17 \pm 0.021$ & $0.22 \pm 0.030$ \\
LS & $0.17 \pm 0.027$ & $0.15 \pm 0.044$
\end{tabular}

$\mathrm{VE}=$ volume of ejaculate, $\mathrm{pH}=\mathrm{pH}$ of semen, $\mathrm{SC}=$ concentration of sperm, $\mathrm{MS}=$ motility of sperm, $\mathrm{AS}=$ abnormal sperm, $\mathrm{DS}=$ dead sperm, $\mathrm{LS}=$ libido score.

Table 5 Estimates of differences between V-line and Saudi Gabali

\begin{tabular}{|c|c|c|c|c|}
\hline \multirow[b]{2}{*}{ Trait } & \multicolumn{2}{|c|}{ Direct additive effects ${ }^{\dagger}$} & \multicolumn{2}{|c|}{ Maternal additive effects ${ }^{\dagger}$} \\
\hline & Units \pm s.e. & $(\%)$ & Units \pm s.e. & $(\%)$ \\
\hline VE $(\mathrm{ml})$ & $0.052 \pm 0.016^{\mathrm{NS}}$ & 8.2 & $0.074 \pm 0.014^{*}$ & 11.7 \\
\hline $\mathrm{pH}$ & $0.202 \pm 0.313^{\mathrm{NS}}$ & 2.7 & $0.294 \pm 0.303^{\mathrm{NS}}$ & 4.0 \\
\hline $\mathrm{SC}\left(10^{6} / \mathrm{ml}\right)$ & $-57.9 \pm 6.1^{*}$ & -12.4 & $-46.6 \pm 5.61^{*}$ & -10.0 \\
\hline MS (\%) & $-4.2 \pm 1.56^{\mathrm{NS}}$ & -6.3 & $-7.26 \pm 1.76^{*}$ & -10.8 \\
\hline AS (\%) & $1.48 \pm 1.16^{*}$ & 12.0 & $1.62 \pm 0.54^{*}$ & 13.2 \\
\hline DS $(\%)$ & $1.02 \pm 0.36^{*}$ & 14.2 & $1.34 \pm 0.28^{*}$ & 18.6 \\
\hline LS & $0.26 \pm 0.113$ NS & 5.8 & $0.31 \pm 0.042^{*}$ & 6.9 \\
\hline
\end{tabular}
breed in direct and maternal additive effects and their standard errors ( \pm s.e.) for semen characteristics and libido score

$\mathrm{VE}=$ volume of ejaculate, $\mathrm{pH}=\mathrm{pH}$ of semen, $\mathrm{SC}=$ concentration of sperm, MS $=$ motility of sperm, AS = abnormal sperm, DS = dead sperm, $\mathrm{LS}=$ libido score.

${ }^{\dagger}$ Percentage of the difference referred to the average of the values for V-line and Saudi Gabali breed; NS = non-significant; * significant at the 5\% level. 
semen-production traits (e.g. concentration and total number of spermatozoa per ejaculate) and some semenquality traits (e.g. percentages of sperm viability, percentage of spermatozoa with normal apical ridge, percentage of sperm morphological abnormalities of neck-mid-piece and percentage of sperm with proximal cytoplasmatic droplet) and those differences were of high magnitude (about $50 \%$ of the actual mean) and in favour of line C for SC and the total number of spermatozoa per ejaculate.

As shown in Table 5, differences in the maternal additive effect for VE $(11.7 \%)$ and LS (6.9\%) were in favour of genes of the V-line carried by the dams of bucks, while these estimates were in favour of Saudi genes for SC $(10.0 \%)$, percentage of AS (13.2\%), percentage of DS (18.6\%) and percentage of MS (10.8\%). Also, García-Tomás et al. (2006a) with two sire lines ( $C$ and $R$ ) observed differences between the two lines in maternal genetic effects and these differences were important for VE $(14 \%)$ and in favour of line $\mathrm{C}$ but in favour of line R for SC $(40 \%)$, total number of spermatozoa per ejaculate $(23 \%)$, mass and individual motility and percentage of spermatozoa with presence of morphological abnormalities of neck-piece. Brun et al. (2002) in France stated that differences between reciprocal crosses for individual motility (trait related to energy metabolism) were of considerable importance; they explained this concept on the basis of sex-linked effects as a result of maternal transmission of mitochondria (cell organites involved in energy metabolism).

Direct and maternal effects for sperms concentration and sperms motility (Table 5) were negative and in favour of Saudi genes. Brun et al. (2002) explained the maternal effects on this trait and they suggested that the differences in maternal genetics effects for the traits related to energy metabolism (sperm motility) could be explained as sexlinked effects on account of maternal transmission of the mitochondria. On the other hand, there is an antagonist relationship between motility and $\mathrm{pH}$ explained by the metabolic activity of the spermatozoa, which release lactic acid and consequently reduce $\mathrm{pH}$. In our case, this relationship is not shown since the sign of the differences is in concordance with this result but the differences are not significant. Concentration and motility have been found to be positively correlated by Battaglini et al. (1992), Bencheikh (1995), Brun et al. (2002) and recently by GarcíaTomás et al. (2006b). This could explain the concordance in the sign of the differences between direct and maternal effects for both traits. It should also be indicated that maternal genetic effects were always of the same sign than direct genetic effects (Table 5), which agree with Brun et al. (2002) for volume and percent of MS and do not agree with García-Tomás et al. (2006b) for concentration and presence of spermatozoa with morphological abnormalities.

\section{Direct and maternal heterosis}

Positive estimates of direct heterosis recorded for VE $(10.6 \%)$, SC (13.5\%), motility of sperm (10.5\%) and LS
(6.2\%) were favourable (Table 6). One of the explanations for positive heterotic effects in the percentage of sperm motility could be that sexual maturation in crossbred males was faster than in purebred males. In other species, such as pigs, it seems that crossbred males could be more advanced in sexual maturity. However, at the adult stage, differences among purebred and crossbred bucks in semen parameters tend to disappear (Wilson et al., 1977; Buchanan and Johnson, 1984). In general, crossbreeding among breeds raised in hot climates was associated with heterotic effects in semen characteristics as stated by El-Ezz et al. (1985) in Egypt and Al-Sobayil and Khalil (2002) in Saudi Arabia.

The estimates of direct heterosis for percentages of abnormal sperm $(-21.5 \% ; P<0.05)$ and dead sperm $(-20.3 \% ; P<0.05)$ were negative and moderate. Brun et al. (2002) reported high variability in the estimates of heterosis in function of the seminal trait since they observed a $6.8 \%$ heterosis in mass motility and a $4.1 \%$ in percentage of MS along with high values of heterosis in SC $(37.5 \%)$, total number of spermatozoa per ejaculate $(37.6 \%)$ and number of MS per ejaculate $(42.3 \%)$. GarcíaTomás et al. (2006a) found high variabilities in the estimates of direct heterosis for several semen characteristics, being practically negligible for sperm normalcy (about $2 \%$ ) but very high for the percentage of spermatozoa with of cytoplasmatic droplet $(57 \%)$.

Estimates of maternal heterosis for different traits were significant and moderate for six traits out of seven (Table 6). The significant and positive estimates of maternal heterosis for VE $(24.0 \%)$, SC $(10.3 \%)$, percentages of motile sperm (21.8\%) and libido of bucks (10.2\%) and the negative and significant estimates for percentages of abnormal sperm $(-9.6 \%)$ and dead sperm $(-14.7 \%)$ show the interest of using crossbred dams to produce the crossbred bucks. It is also interesting to note that the values of the individual and maternal heterosis are very positive to determine the semen characters of the newly founded synthetic lines (Saudi 2 and 3 lines, Table 1).

Table 6 Estimates of direct and maternal heterosis and their standard errors ( \pm s.e.) for semen characteristics and libido score

\begin{tabular}{lcrlcr}
\hline \hline & \multicolumn{2}{c}{ Direct heterosis $^{\dagger}$} & & \multicolumn{2}{c}{ Maternal heterosis ${ }^{\dagger}$} \\
\cline { 2 - 3 } \cline { 5 - 6 } Trait & Units \pm s.e. & $(\%)$ & & Units \pm s.e. & $(\%)$ \\
\hline VE (ml) & $0.067 \pm 0.010^{*}$ & 10.6 & & $0.151 \pm 0.097^{*}$ & 24.0 \\
PH & $0.120 \pm 0.233^{\mathrm{NS}}$ & 1.6 & & $0.272 \pm 0.208^{\mathrm{NS}}$ & 3.7 \\
SC (10\%/ml) & $63.0 \pm 6.19^{*}$ & 13.5 & & $48.2 \pm 4.46^{*}$ & 10.3 \\
MS (\%) & $7.04 \pm 1.76^{*}$ & 10.5 & & $14.6 \pm 2.87^{*}$ & 21.8 \\
AS (\%) & $-2.65 \pm 0.58^{*}$ & -21.5 & & $-1.18 \pm 0.38^{*}$ & -9.6 \\
DS (\%) & $-1.46 \pm 0.52^{*}$ & -20.3 & & $-1.06 \pm 0.21^{*}$ & -14.7 \\
LS & $0.28 \pm 0.06^{*}$ & 6.2 & $0.46 \pm 0.03^{*}$ & 10.2 \\
\hline \hline
\end{tabular}

$\mathrm{VE}=$ volume of ejaculate, $\mathrm{pH}=\mathrm{pH}$ of semen, $\mathrm{SC}=$ concentration of sperm, $M S=$ motility of sperm, $A S=$ abnormal sperm, $D S=$ dead sperm, $L S=$ libido score.

'Percentage of the heterosis referred to the average of the values for V-line and Saudi Gabali breed; NS = non-significant; * significant at the $5 \%$ level. 
Table 7 Estimates of recombination losses $\left(\mathrm{R}^{\prime}\right)$ and their standard errors ( \pm s.e.) for semen characteristics and libido score

\begin{tabular}{lc}
\hline \hline Trait & $R^{\prime \dagger} \pm$ s.e. \\
\hline VE $(\mathrm{ml})$ & $-0.087 \pm 0.017^{*}$ \\
$\mathrm{pH}$ & $-0.021 \pm 0.049^{\mathrm{NS}}$ \\
SC $\left(10^{6} / \mathrm{ml}\right)$ & $-24.1 \pm 10.7^{\mathrm{NS}}$ \\
$\mathrm{MS}(\%)$ & $-1.12 \pm 0.28^{\mathrm{NS}}$ \\
AS $(\%)$ & $-0.068 \pm 0.118^{\mathrm{NS}}$ \\
DS $(\%)$ & $-0.37 \pm 0.114^{\mathrm{NS}}$ \\
LS & $-0.071 \pm 0.014^{\mathrm{NS}}$ \\
\hline \hline
\end{tabular}

$\overline{\mathrm{VE}}=$ volume of ejaculate, $\mathrm{pH}=\mathrm{pH}$ of semen, $\mathrm{SC}=$ concentration of sperm, $\mathrm{MS}=$ motility of sperm, $\mathrm{AS}=$ abnormal sperm, $\mathrm{DS}=$ dead $\mathrm{sperm}, \mathrm{LS}=$ libido score.

${ }^{+} \mathrm{NS}=$ non-significant; ${ }^{*}$ significant at the $5 \%$ level.

\section{Recombination losses}

The recombination losses were always non-significant for all traits studied (Table 7) except that the VE that was significant but with low magnitude. These results indicate that recombination losses for these traits were of limited importance in crossbred bucks when compared with direct heterosis. In this concept, we found that the estimates of direct heterosis for the majority of the studied traits (Table 6) were generally the largest.

\section{Conclusions}

Significant estimates of direct and maternal additive effects for most semen characters showed the superiority of the Saudi Gabali breed compared with the V-line. Moreover, the majority of semen parameters were improved in crossbred bucks relative to purebred bucks of V-line or Saudi Gabali.

The signs and values of individual and maternal heterosis were favourable to the expected semen characters of crossbred bucks, and of bucks of synthetic lines derived from crosses between V-line and Saudi Gabali.

\section{Acknowledgements}

This project was financially supported by King Abdulaziz City for Science and Technology in Saudi Arabia. We are grateful to one referee for helpful discussion and comments.

\section{References}

Al-Sobayil $\mathrm{K}$ and Khalil MH 2002. Semen characteristics of bucks in crossbreeding project involving Saudi Gabali with V-Line rabbits in Saudi Arabia. Proceedings of the Third Scientific Conference on Rabbit Production in Hot Climates, Hurgada, Egypt, pp. 151-163.

Alvariño JMR 2000. Reproductive performance of male rabbits. Proceedings of the Seventh World Rabbit Congress, Valencia, Spain, vol. A, pp. 13-35.

Alvariño JMR, López FJ, Del Arco JA, Bueno A and Torres R 1996. Effect of semen concentration on rabbit artificial insemination with fresh or 24 hours stored semen. Proceedings of the Sixth World Rabbit Congress, Toulouse, France, vol. 2, pp. 3-5.

Arroita Z, Falcete MV, Martin Rillo S, DeAlba C, Moreno C, Qudad MJ and Rafel $O 2000$. Effect of collection frequency on production, quality and storage of young bucks semen. Proceedings of the Seventh World Rabbit Congress, Valencia, Spain, vol. A, pp. 81-87.

Baselga M, García ML, Sánchez JP, Vicente JS and Lavara R 2003. Analysis of reproductive traits in crosses among maternal lines of rabbits. Animal Research 52, 473-479.

Battaglini M, Castellini C and Lattaioli P 1992. Variability of the main characteristic of rabbit semen. Journal of Applied Rabbit Research 15, 439-446.

Bencheikh N 1995. Effet de la fréquence de collecte de la semence sur les caractéristiques du sperme et des spermatozoïdes récoltés chez le lapin. Annales de Zootechnie 44, 263-279.

Boussit D 1989. Reproduction et insémination artificielle en cuniculture. Association Française de Cuniculture, Lempdes, Paris, p. 234.

Brun JM, Theau-Clement M and Bolet G 2002. Evidence for heterosis and maternal effects on rabbit semen characteristics. Animal Research 51, 433-442.

Buchanan DS and Johnson RK 1984. Reproductive performance for 4 breeds of swine-crossbred females and purebred and crossbred boars. Journal of Animal Science 59, 948-956.

Castellini C, Lattaioli P, Dal Bosco A, Minelli A and Mugnai C 2003. Oxidative status and semen characteristics of rabbit buck as affected by dietary vitamin E, C and n-3 fatty acids. Reproduction, Nutrition, Development 43, 91-103.

Chemineau P, Cagnie Y, Guerin Y, Orgeur P and Vallet JC 1991. Training manual on artificial insemination in sheep and goats. Food and Agriculture Organization of the United Nations, Rome.

Dickerson GE 1992. Manual for evaluation of breeds and crosses of domestic animals. Food and Agriculture Organization of the United Nations, Rome.

Egea De Prado MD and Roy Perez T 1992. Analysis of semen characteristics of rabbit buck for artificial insemination. Results of fertility. Boletín de Cunicultura $59,49-51$.

El-Ezz ZRA, Kosba HA, Hamdy SM and Soliman FN 1985. Effect of crossing on semen characteristics in rabbits. Beiltrge zur Tropischen Landwirtschaft und Veterinarmedizin 23, 249-434.

Estany J, Baselga M, Blasco A and Camacho J 1989. Mixed model methodology for the estimation of genetic response to selection in litter size of rabbits. Livestock Production Science 21, 67-75.

García-Tomás M, Sánchez J, Rafel 0, Ramon J and Piles M 2006a. Heterosis, direct and maternal genetic effects on semen quality traits of rabbits. Livestock Science 100, 111-120.

García-Tomás M, Sánchez J, Rafel O, Ramon J and Piles M 2006b. Variability, repeatibility and phenotypic relationship of several characteristics of production and semen quality in rabbit. Animal Reproduction Science 93, 88-100.

Kuzminsky G, Fausto AM and Morera P 1996. Morphological abnormalities of rabbit spermatozoa studied by scanning electron microscope and quantified by light microscope. Reproduction, Nutrition, Development 36, 565-575.

Minelli G, Zucchi P, Luzi F and Cavani C 1999. Effect of high dietary vitamin C and $\mathrm{E}$ administered alone or mixed: influence on rabbit semen characteristics. World Rabbit Science 7, 31-31.

Neumaier A and Groeneveld E 1998. Restricted maximum likelihood of covariances in sparse linear models. Genetics, Selection, Evolution 30, 3-26.

Vicente JS, Viudes De Castro MP, Lavara R and Lavara F 2000. Effect of male line on prolificacy from does inseminated with low sperm doses. Proceedings of the Seventh World Rabbit Congress, Valencia, Spain, vol. A, pp. 273-277. Wilson ER, Johnson RK and Wettemann RP 1977. Reproductive and testicular characteristics of purebred and crossbred boars. Journal of Animal Science 44, 939-947.

Wolf J 1996. User's manual for the software package CBE, version 4.0 (A universal program for estimating crossbreeding effects). Research Institute of Animal Production, Prague-Uhrineves, Czech Republic. 